\title{
Ka titiro whakamua - Looking to the future
}

Kia ora kotou katoa. My name is Stephanie Woodley and, as the new editor, I am pleased to welcome you to this issue of the New Zealand Journal of Physiotherapy (NZJP). By way of introduction, I graduated as a physiotherapist in 1995, and after practising in New Zealand and overseas for a number of years, I took the opportunity to undertake postgraduate study. This in turn led to an academic position, and I have been based in the Department of Anatomy, University of Otago for the past 12 years. I am passionate about education, physiotherapy and anatomy; in my current role at the university I am involved in a diverse range of activities that include teaching undergraduate and postgraduate physiotherapy and science students, and providing evidence-based workshops and research presentations for clinicians. I have a particular interest in musculoskeletal conditions of the pelvis, hip and lower limb; and I work with a range of researchers to produce research that is relevant and translatable to clinical practice. I have been privileged to work as an associate editor for the NZJP since 2005, which means I also enjoy the varied aspects and challenges associated with writing, reviewing and editing! It is a real honour to be given the opportunity to take on the role of editor. I look forward to the continued relationship with our wider team of dedicated personnel, including the honorary editorial committee, Physiotherapy New Zealand staff and our valued peer reviewers as well as our authors and readership, all of whom are a vital in shaping our journal.

It is important that we celebrate past achievements. I would like to acknowledge the outstanding contribution that Professor Leigh Hale has made to the NZJP, particularly through her leadership as editor over the last eight years. During this time, Leigh has focused on continuing to build the profile and standards of the journal both nationally and internationally, while also valuing the niche that it provides for research unique to Aotearoa New Zealand (Hale, 2018). In today's world there is an endless array of places in which researchers can publish, and while the NZJP is smaller than many other health-related journals, Leigh has ensured that the content is of a consistently high quality, while at the same time, encouraging contributions from new and emerging researchers and clinicians.

Under Leigh's guidance, in 2018 the NZJP was listed on Scopus - the "largest abstract and citation database of peer-reviewed literature", containing over 71 million references (Elsevier, 2018). As we well know, academic journal publishing has evolved rapidly over the past decade or so, and printed material has largely been replaced by digitised files. This has resulted in a shift in readership patterns, with journal issues that were once read as an integrated whole, giving way to individual paper downloads and reads (Norman, 2013). Hence, having an online, open access presence (publications from the last seven years are available free of charge on the Physiotherapy New Zealand website) is essential in our current and rapidly changing environment and, together with our listing on Scopus, should help enhance the journal's visibility and profile.
The Scopus indexing platform has many varied features, and I would like to touch on two of these: CiteScore and PlumX Metrics. CiteScore provides a measure of citation impact, similar to that of journal impact factors (Clarivate Analytics, formerly Thomson Reuters), except this metric is calculated over a threeyear rather than a two-year period. As the NZJP has been listed on Scopus for just over one year, it will take at least another 18 months until we can expect to see an annual CiteScore metric for the journal (Scopus, n.d.a). However, journal-based citations may not be the best measure of impact - many of us will often read papers that we do not end up citing, and our research may also have the potential to influence other disciplines and stakeholders. As such, altmetrics (short for alternative metrics) have emerged, described as "web-based metrics for the impact of scholarly material, with an emphasis on social media outlets as sources of data" (Shema, Bar-llan, \& Thelwall, 2014, p. 1019). This interesting measure of the "societal" impact of research data (Bornmann, 2014) is another feature offered by Scopus, enabled by the integration of PlumX Metrics in 2017 (Scopus, n.d.b). Five metric categories are available, including citations, usage (e.g. downloads, views), captures (including Mendeley reader counts), mentions (e.g. blog posts, news articles, reviews) and social media (e.g. likes, shares, tweets). While altmetrics may provide a more complete, timely perspective of research uptake compared to traditional citation metrics, a number of disadvantages have also been highlighted, including the reliance on commercial providers (e.g. Twitter), concerns relating to data quality (e.g. bias in the usage of social media platforms and uncertainty surrounding measurement standards), the lack of systematic evidence on altmetrics and concerns about manipulation of altmetrics (Bornmann, 2014). However, going forward, it will be interesting to use PlumX Metrics to track our journal articles; the resulting data may provide valuable insights into our readership and the way in which people interact with our publications in the online environment.

Bearing in mind the impact that a body of research can have on the development of physiotherapy practice, this year the honorary editorial committee has introduced "impact statements" which authors will write as an accompaniment to their published papers. The intention of an impact statement is to provide a clear and short (100 words) outline of the key findings of the article that is understandable to a lay person, and which can be published in Physio Matters alongside appropriate imagery. In the upcoming months we will also look at other forms of active post-publication strategies and different initiatives as they pertain to use of media to encourage the dissemination of work published in the NZJP.

The honorary editorial committee is cognisant that the NJZP is a small publication on the international stage and, accordingly, we have set ourselves realistic goals. However, in developing our strategic plan and looking to the future, we have highlighted our desire to continue to improve the quality of publication content in the NZJP and to increase the reach, visibility and impact of the NZJP as a professional publication. These goals 
tie in nicely with the mission of the NZJP, which is to "serve the members of Physiotherapy New Zealand by publishing content that reflects excellence in research and professional issues relevant to the New Zealand and international communities". The NZJP accepts a wide range of manuscripts and continues to offer a number of benefits to authors - we support clinicians new to publishing and early stage researchers, provide open access publication, are listed on Scopus, will publish your paper free of charge, and also award a biennial prize for the best publication! We plan to build on these foundations to enhance the reputation and excellence of our journal, and publish papers that have the potential to change what you do. Please do send me your feedback - we look forward to the continued engagement with our readership and the wider physiotherapy community!

On a final note, on behalf of the wider NZJP team, I wish to convey our sincere condolences to those who have been affected following the tragic events that unfolded in Christchurch on the 15th of March, particularly the people of Christchurch and our Muslim communities. Aotearoa New Zealand has been forever changed, but by showing kindness, care and inclusiveness to those around us, we will be able to move forward together, as one.

Ngā mihi,

Stephanie Woodley

Editor

New Zealand Journal of Physiotherapy

stephanie.woodley@otago.ac.nz

\section{REFERENCES}

Bornmann, L. (2014). Do altmetrics point to the broader impact of research? An overview of benefits and disadvantages of altmetrics. Journal of Informetrics 8, 895-903. https://doi.org/ 10.1016/j.joi.2014.09.005

Elsevier (2018). Scopus. An eye on global research: 5,000 publishers. Over $71 \mathrm{M}$ records and 23,700 titles. Retrieved from https://www.elsevier. com/_data/assets/pdf_file/0008/208772/ACAD_R_SC_FS.pdf

Hale, L. (2018). Why you should publish with us, the New Zealand Journal of Physiotherapy. New Zealand Journal of Physiotherapy, 46(1), 5. https://doi. org/10.15619/NZJP/46.1.02

Norman, E. R. (2013). 6.11: Maximizing research visibility, impact, and citation: Tips for editors and authors. In P. Smart, H. Maisonneuve \& A. Polderman (Eds.) Science editors handbook, (2 ${ }^{\text {nd }}$ ed., pp. 1-4). European Association of Scientific Editors. Retrieved from http://www.ease.org.uk/ wp-content/uploads/6-11.pdf

Scopus (n.d.a). Journal metrics - FAQs. Retrieved 7 March 2019 from https:// journalmetrics.scopus.com/index.php/Faqs

Scopus (n.d.b) PlumX metrics. Retrieved 7 March 2019 from https://blog. scopus. com/topics/plumx-metrics

Shema, H., Bar-llan, J., \& Thelwall, M. (2014). Do blog citations correlate with a higher number of future citations? Research blogs as a potential source for alternative metrics. Journal of the Association for Information Science and Technology, 65(5), 1018-1025. https://doi.org/10.1002/asi.23037 